\title{
Glaciodynamic context of subglacial bedform generation and preservation
}

\author{
Ghris D. Glark \\ Department of Geography, University of Sheffield, Sheffield S10 2TN, England
}

\begin{abstract}
Subglacially-produced drift lineations provide spatially extensive evidence of ice flow that can be used to aid reconstructions of the evolution of former ice sheets. Such reconstructions, however, are highly sensitive to assumptions made about the glaciodynamic context of lineament generation; when during the glacial cycle and where within the ice sheet were they produced. A range of glaciodynamic contexts are explored which include: sheet-flow submarginally restricted; sheet-flow pervasive; sheetflow patch; ice stream; and surge or re-advance. Examples of each are provided. The crux of deciphering the appropriate context is whether lineations were laid down time-transgressively or isochronously. It is proposed that spatial and morphometric characteristics of lineations, and their association with other landforms, can be used as objective criteria to help distinguish between these cases.

A logically complete ice-sheet reconstruction must also account for the observed patches of older lineations and other relict surfaces and deposits that have survived erasure by subsequent ice flow. A range of potential preservation mechanisms are explored, including: coldbased ice; low basal-shear stresses; shallowing of the deforming layer; and basal uncoupling.
\end{abstract}

\section{INTRODUCTION}

Reconstructions of the geometry of former ice sheets and their evolution through time can be made by piecing together the fragmentary geomorphological and geological evidence that they leave behind. Changes of ice-sheet extent can be reconstructed utilizing stacked glacial-nonglacial deposits to define the position of the ice-sheet perimeter in space and time. Internal components of ice-sheet geometry, the flow patterns and ice divides, can be reconstructed from ice-flow indicators such as erratic dispersal, glacial striae and subglacial bedforms. Of these, subglacial bedforms provide the most frequent and spatially extensive evidence of ice flow which is often used to build or support ice-sheet reconstructions (e.g. Dyke and Prest, 1987; Boulton and Clark, 1990a, b; Kleman and others, 1997).

Subglacial bedforms include flutes, megaflutes, drumlins, and megalineations (Clark, 1993), all of which are drift landforms produced parallel to ice flow, hereafter termed as subglacial drift lineations. Ribbed (Rogen) moraine are also bedforms, but are not dealt with in this paper. Together, they probably cover over $80 \%$ of former ice-sheet beds and have important palaeoglaciological information encoded within them. If we had complete knowledge of their pattern, distribution and genesis, we would be able to make unequivocal reconstructions of aspects of the geometry of the ice sheets that produced them. Such knowledge has remained elusive, leading to a range of competing theories of formation which, when applied to a sample of the bedform population, has inevitably led to widely varying reconstructions of former ice sheets. This is illustrated by the radical changes of view regarding Laurentide ice sheet geometry over the last 40 years (cf. Prest, 1990). Because of different assumptions made about the glaciodynamic context of bedform generation, some reconstructions produced a large singledomed model and others a smaller multiple-domed ice sheet. These are large differences in terms of overall ice volume, height and surface profile and have major implications for palaeoclimate, sea level and isostasy.

At the simplest level, subglacial lineations can be used to deduce the orientation and direction of ice flow. As they are formed by the action of ice moving over the substrate, it is also widely presumed that this indicates a warm-based thermal regime at the time of generation (e.g. Kleman and Borgström, 1996). In order to derive from them a greater level of palaeoglaciological information, we need to know:

\section{(1) What were the processes of generation?}

There are numerous qualitative hypotheses, inferences and associations that attempt to relate landform and process, and a number of theories. Conclusive proof has not been forthcoming. According to different theories of formation, a drumlin field, for example, could be taken to infer widespread subglacial sediment deformation (Boulton, 1987) or a subglacial flood event (Shaw, 1994). Ribbed moraines could be used to infer zones of compressive ice flow (Bouchard, 1989) or extending flow at a transition in basal thermal regime (Hättestrand, 1997).

\section{(2) What was the glaciodynamic context of generation?}

If we knew the answer to (1), it would be possible to deduce logically their glaciodynamic context; where, beneath the ice sheet were they generated? We are left wondering whether they formed close to the margins or over large areas within internal portions of ice sheets, or were they restricted to certain glaciodynamic phenomena, such as in ice streams or surges?

This paper focuses on the second and more infrequently 
posed question, as it is critical in terms of how we use landform patterns to build reconstructions of ice sheets. The key questions are:

(1) Under which portions of ice sheets were bedforms generated?

(2) When, during the glacial cycle, were they generated?

(3) How can they be preserved beneath subsequent ice flow?

(4) What are the implications for palaeoglaciology?

\section{GLACIODYNAMIC GONTEXT OF BEDFORM GENERATION}

As former ice sheets produced bedforms in abundance, it is likely contemporary ice masses are doing the same. If geophysical methods could remotely sense the bed of contemporary ice sheets in enough detail, we could build up a picture of the glaciodynamic context of particular bedform types. Megalineations, for example, might only be found under active ice streams. Such associations between glaciology and landforms could then be used in inverse mode to convert maps of glacial geomorphology of exposed ice-sheet beds into the palaeoglaciology that produced them. Until such time when this approach is practical, we are forced to either make gross assumptions or to examine the now-exposed beds of ice sheets and try and relate the bedform patterns to our knowledge of ice-sheet geometry and history.

This approach, however, has led to some confusion, as subglacial bedforms have often been used to bolster or fill gaps in a reconstruction, without due regard to the uncertainties of their location and timing of generation. Critical assumptions have often been made without explicit comment, and the questions explored in this paper have often been circumvented by simplifying flow patterns into "generalized flowlines". In this section, we review the range of possible assumptions and modes of interpretation, provide examples from the literature and critically examine these alternatives.

Subglacial lineations tend to exist as collections of landforms rather than as isolated individuals, a field of drumlins being the classic example. Once the landforms are mapped, it is relatively straightforward to group similar landforms into spatially coherent and distinctive patterns which Clark $(1994,1997)$ has called flow-sets. This grouping is usually performed by subjective visual pattern recognition, based on some combination of the following criteria:

(1) Parallel concordance: each landform should have a similar orientation to its neighbours.

(2) Close proximity: each landform should be closely packed with its neighbours. The spacing will typically be of the order of up to two to three times the dimensions of the landform.

(3) Similar morphometry: neighbouring landforms usually display similar morphometry.

To be able to use these flow-sets to derive information about the ice sheet, we need to ascertain, or make assumptions, about their glaciodynamic context; do they record submarginal, or interior flow patterns or the activity of individual ice streams of lobes? Were the flow-sets generated under buildup, maximum or retreat stages of the ice sheet?

Following from Clark (1994) and Kleman and Borgström (1996), we can build a logical argument as follows. All land-
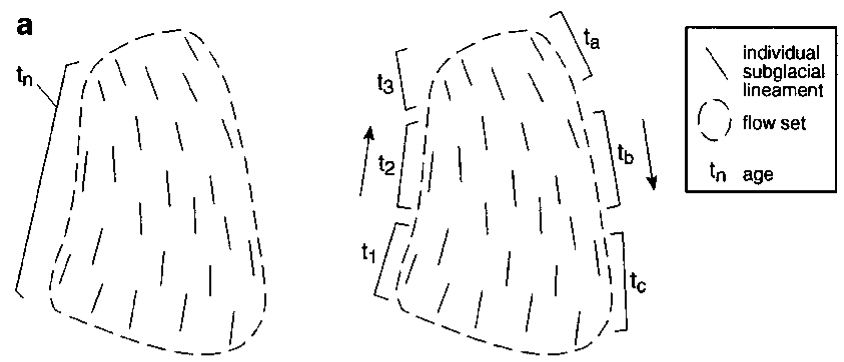

b
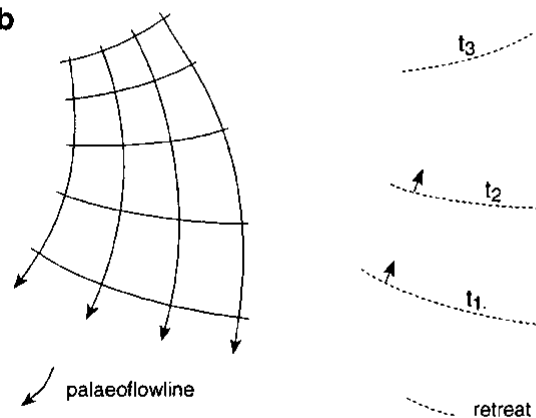

- form line ('contour')

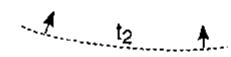

A

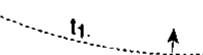

$\cdots$ retreat isochrons

c

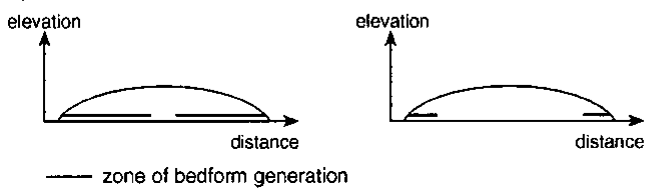

Fig. 1. (a) Flow-set of subglacial drift lineations that may have formed isochronously at time $t_{\mathrm{n}}$, or time-transgressively from $t_{1}-t_{3}$ or $t_{\mathrm{a}}-t_{\mathrm{c}}$. (b) Alternative modes of interpretation of such a pattern. (c) Consequent presumptions about glaciodynamic context, as either along extensive palaeo-flowlines or restricted to submarginal positions.

forms within a flow-set may have been created either synchronously or incrementally at successive time-steps. This is demonstrated in Figure 1, where individual lineations forming a flow-set (Fig. la) may either have all formed at a single point in time or successively through time. For the former, we can use the flow-set to infer actual palaeo-flowlines and draw form lines perpendicular to these, representing the surface form of the ice sheet (Fig. 1b). For the latter case, the most likely explanation is that the bedforms were generated in a zone behind a retreating ice margin $\left(t_{1}-t_{3}\right.$ in Fig. la and $b$ ), thus laying down a time-transgressive pattern, that becomes younger in an inward direction. The synchroneity of bedform production within a flow-set is therefore the key to answering the questions posed earlier: under what portions of the ice sheet were they generated, and when during the glacial cycle? Our main question therefore reduces to: was the flow-set produced isochronously or time-transgressively?

A hypothetical range of glaciodynamic contexts, under which subglacial lineations could form, are illustrated in Figure 2. It is assumed that the generation of subglacial lineations is restricted to warm-based ice and appropriate "envelopes" of basal shear-stress, sediment supply, sediment rheology and hydrology. These conditions are likely to vary considerably over local and regional-scale distances and over time (cf. Piotrowski and Kraus, 1997). At the ice-sheet scale, lineations cannot form beneath ice divides because of very low basal shear-stresses in these areas, i.e. little or no horizontal velocity component, and cold-based ice will simi- 


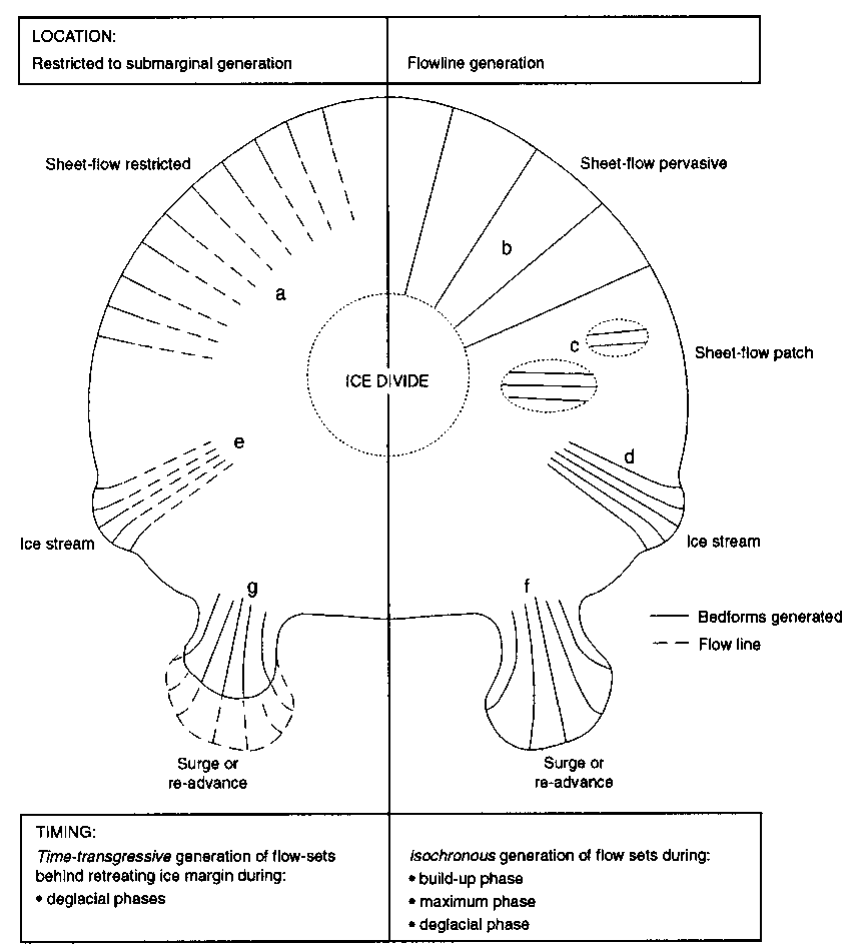

Fig. 2. Schematic ice sheet illustrating range of glaciodynamic contexts under which subglacial lineations may be generated; time-transgressive (left) and isochronous generation (right).

larly inhibit bedform production. The schematic ice sheet (Fig. 2) is subdivided into a bedform record restricted to submarginal generation (left-hand side) and hence time-transgressive formation, and a record that is created by isochronous formation (right-hand side). Each glaciodynamic context is discussed below.

\section{(a) Sheet flow, submarginally restricted}

This is the most commonly assumed glaciodynamic context for subglacial lineations: that they are generated in a submarginal position, i.e. restricted to about $10-100 \mathrm{~km}$ behind the margin. The main basis for this assumption lies in a frequent land-system association between drumlin patterns and end moraines. A review of the characteristics of 95 drumlin fields led Patterson and Hooke (1995) to list this proximity to ice margins as a requisite characteristic of drumlins, and in almost all discussions of drumlin genesis the submarginal context is assumed The glaciological basis for the restriction is less certain, but relative to the rest of the ice sheet, ice thicknesses should be at a minimum, and flow velocities should be high because we are close to the typical position of the equilibrium line. Many argue (e.g. Smalley and Unwin, 1968) that the formation of lineations is restricted to a narrow and critical range of such conditions.

According to this glaciodynamic context, ice-sheet-wide patterns of bedforms are built up time-transgressively behind a retreating ice margin. Examples of ice-sheet reconstructions using this assumption include Bryson and others (1969), Boulton and others (1985) and Lundqvist (1986).

\section{(b) Sheet flow, pervasive}

Alternatively, it may be that lineations do not require such a narrow range of critical conditions (ice thickness, velocity etc.) for their formation and are produced over far more widespread areas. The lineation generation zone could extend from close to the margin to near the divide. According to this assumption, lineation patterns were generated approximately isochronously and, if preserved during deglaciation, can therefore be used to reconstruct palaeo-flowlines and divide position within the ice sheet. Examples of reconstructions along these lines include Shilts (1980) and Prest (1984).

\section{(c) Sheet flow, patch}

A variant or subset of the above is that whilst lineation generation may occur across a wider range of subglacial conditions, it is also critically controlled by other factors that restrict its occurrence to patches. This can be idealized as a lineament-generation switch that may be turned on and off, thus inscribing flow patterns at snapshots in time. Sheetflow patch bedforms were formed isochronously and record the flow geometry at their time of formation.

Some of the cross-cutting lineation patterns of the Laurentide ice sheet (Boulton and Clark, 1990a, b) and Fennoscandian ice sheet (Kleman and others, 1997) have been interpreted as sheet-flow patches leading to reconstructions of migrating ice divides.

\section{d) Stream-flow, pervasive}

Following from the logic whereby lineament generation is restricted to a zone of rapid-flow velocities in a submarginal position, we can seek similar glaciodynamic contexts. Ice streams are such examples, because of their high velocities and thin ice. If lineament generation occurs here, then it is reasonable to suppose that given other criteria (sediment supply, hydrology etc.) they will be produced pervasively over the fast-flow zone. The pattern of lineaments may form isochronously and thus record the activity of an ice stream at a point in time. Examples of such a geomorphological record are the Transition Bay and M'Clintock Channel flow patterns in Arctic Canada, which are interpreted as the record of episodes of ice-stream activity (Dyke and Morris, 1988; Hodgson, 1994). A preserved geomorphological record of an isochronous ice stream implies that the ice stream "turned off" and that the landforms were subsequently preserved beneath a deglaciating ice sheet.

\section{(e) Stream-flow, submarginally restricted}

Avariant of the ice-stream record above could be the situation whereby ice-stream activity persisted during margin retreat. This sustained fast ice flow would seek to continuously reorganize the bed during retreat and may lead to a time-transgressive record of flow. Ice streams are known to increase in velocity from their onset position to terminus, and so most reorganization could be expected close to the margin. Lineation patterns of the Fennoscandian and Laurentide ice sheets have been interpreted to record such time-transgressive retreat of active streams (Punkari, 1995; Dongelmans, 1995; Patterson, 1998). Stokes and Clark (1999) specifically discuss the geomorphological record of former ice streams.

\section{(f) Surge or re-advance, pervasive}

It has frequently been the case that lineation patterns have been interpreted to represent a record of ice-sheet re-advances or surges. A notable example is the Drumlin Readvance phase of the Irish ice sheet (Synge, 1970). A belt of drumlins, constrained to the south by a moraine system, were 
taken to record a major re-advance stage of the ice sheet. Substantiation of actual re-advance is best achieved from overridden sediments, landforms and biological remains or by proglacial lake-sediment records. But in this case, the explanation seems to have come from an assumption that directly linked drumlin formation to an advancing ice sheet. Early workers perhaps mistakenly equated fast ice flow, presumed necessary to build lineations and moraines, as implying a re-advance. However, we have seen above that there are plenty of other glaciodynamic explanations for fast ice flow. The Cochrane re-advances (Dredge and Cowan, 1989) of the southern margin of the Laurentide ice sheet provide good examples of substantiated re-advances or surges which produced well-defined isochronous lineament patterns.

\section{(g) Surge or re-advance, submarginally restricted}

We must also consider the possibility that a surge or readvance may lay down a time-transgressive record in an outward-younging manner (cf. Kleman and Borgstrøm, 1996). This could happen as the submarginal zone of lineament generation steadily advanced outwards along with the advancing margin. Such an outward-younging pattern requires a trailing zone (and mechanism) of preservation, otherwise these features would become erased by further ice flow. No examples of this type are known.

The sheet-flow pervasive (b) and sheet-flow patch (c) contexts are distinct from all the others in that they imply lineament generation beneath thick as well as thin ice. The submarginal contexts ( $a$, e and $g$ ) clearly demand generation only under thin ice. Types (d) and (f) produce lineament generation over a large proportion of the semi-span of the ice sheet, but do so within an ice stream or surge which has a very low ice-surface profile and thin ice. A key question therefore is: can bedform generation be produced under thick ice with high normal stresses? For the deforming bed or catastrophic flood theories, this largely depends on subglacial hydrology. High pore-water pressures (pwp) are required to lower the effective pressure (overburden pressure-pwp) enough to permit deforming-bed processes, or hydrostatic pressure needs to be sufficiently high to permit decoupling of the ice sheet from the bed in order to accommodate catastrophic flooding. These factors tend to argue against production under thick ice, but demand better knowledge of subglacial meltwater production, storage and conductivity.

An underlying assumption that pervades this paper and much of the subglacial bedform literature in general is that lineations are either restricted to, or preferentially developed, under fast ice flow. Although this long-held association between lineation occurrence-elongation ratio with ice velocity (e.g. Hollingworth, 1931; Clark, 1993) has never been proven, it remains the main paradigm. Glaciodynamic contexts, (a) and $(\mathrm{d}-\mathrm{g})$ all conform to this and require fast-flow velocities which may arise from either: high (mass-balance driven) velocities and driving stress in the submarginal situation (a); or from situations with much lower driving stress, but accompanied by low yield strength of the underlying bed, such as in ice streams or surge lobes $(d-g)$. Context (b) (sheet-flow pervasive) stands out from these in that it produces lineations under a range from high- to low-flow velocities. If, as Clark $(1993,1994)$ argues, that the length of a lineation must be limited by the flow velocity and the duration of the generating episode (i.e. limited by ice flux), then for the former contexts ( $a$ and $d-g$ ) the lineations must have been produced rapidly under fast ice and the latter (b) produced under slow-moving ice, but for much greater duration. This difference provides circumstantial evidence against sheet-flow pervasive (b), as its generation requires stable flow geometries for long periods of time. Whereas our understanding of the glacial history of the Laurentide ice sheet, for example, increasingly demonstrates that flow geometries were far from static and were likely continuously changing through the evolution of the ice sheet (e.g. MacAyeal, 1993 ).

Glaciodynamic contexts $(\mathrm{a}-\mathrm{f})$ have all been used as explanations for lineation patterns and have, to varying degrees, been used to build or bolster ice-sheet reconstructions. We must also consider that the generation of some landforms may actually require a combination of glaciodynamic contexts, rather than a single generating episode under constant subglacial conditions. Examples of such landforms are ribbed moraine and horned crag-and-tails, for which Hättestrand (1997) and Jansson and Kleman (1999) invoke specific changes in thermal regime in order that they may be produced.

Until we are sure of processes of formations of subglacial bedforms, it will be hard to apply glaciological understanding to ascertain which contexts are feasible and most frequent. The best we can do at the present time, when building ice-sheet reconstructions is to recognize this diverse range of glaciodynamic contexts and try to find criteria by which we can distinguish between them or, at the very least, make explicit statements about any assumptions we use. The next section addresses this problem.

\section{GRITERIA TO DISTINGUISH TIME-TRANSGRESSIVE AND ISOGHRONOUSLY GENERATED DRIFT LINEATIONS}

In this section we argue that lineations within a flow-set, generated time-transgressively or isochronously, will display different and perhaps distinctive, spatial and morphometric characteristics. Table 1 summarizes how the three main factors of ice thickness, flow topology and stability permit predictions to be made of the consequent lineation characteristics. Time-transgressive generation is conducted close behind a retreating ice margin, where we would typically expect thin ice cover, lobate margins and rapidly varying flow patterns with occasional margin stillstands during recession. This contrasts with isochronous generation, which predominantly forms some distance from the margins where we would expect thicker ice with internal rather than marginal flow patterns and, consequently, much greater stability. It is argued that these contrasting conditions should produce distinctive lineation patterns.

The planform shape of terrestrial ice-sheet margins are usually crenulate, consisting of a series of lobes produced by strongly diverging flow patterns. This characteristic splaying flow pattern is markedly distinct from the types of flow topology experienced within the interior portions of the ice sheet. This provides a useful criterion for identifying lineation flow-sets produced submarginally. Added to this is the nature of lineation patterns that should accrue as these splayed flow patterns retreat (Clark, 1994). As lobes are typically of low profile with thin ice cover, the trajectory of lobe retreat is highly influenced by topography and subglacial geology. This is likely to lead to individual lobes changing shape and 


\section{Time-transgressive generation}

Flow-set built up incrementally
Formed close to ice margins: Thin ice

Lobate margin patterns

Rapidly varying flow directions
Predominantly lobate or splaying flow patterns Flow-pattern correspondence to local topography

Flow-set likely to contain internal cross-cutting lineations Low parallel conformity between lineations

Spatial variation in lineation morphometry will contain abrupt discontinuities

Probable landform association with end moraines

Probable landform association with eskers
Isochronous generation

Flow-set generated rapidly "in an instant"
Formed away from ice margins: Range of ice thickness Conforms to internal, rather than marginal flow patterns

Greater stability of flow directions
Predominantly parallel flow patterns

Little or no flow-pattern correspondence to local topography No cross-cutting lineations within flow-sets

High parallel conformity between lineations

Spatial variation in lineation morphometry will be gradual

No landform association with moraines

No landform association with eskers position as they retreat, producing a complex flow-pattern record. Under these conditions, it is likely the lineation record will display cross-cutting and superimpositions. In inverse mode, we can thus interpret a broadly splayed set of lineations with cross-cuts as representing a time-transgressive flow-set, recording margin retreat. A good example of this is demonstrated by Mooers (1989) for part of the southern margin of the Laurentide ice sheet.

When the bedform-generating episode is short, in relation to how quickly flow directions may vary (i.e. isochronous generation), the lineations should display highparallel conformity with their neighbours and aspects of their morphometry, such as elongation ratio, should vary in a systematic and gradual manner over space. This is because the whole flow-set formed in-an-instant and its characteristics should reflect this. The converse situation, whereby flow patterns actually vary during the bedformgenerating episode, will produce a less well-ordered lineation pattern. This is what we expect of time-transgressive flow-sets. Such lineations may have slightly different orientations than their neighbours (low-parallel conformity) and spatial variations in morphometry are likely to contain abrupt discontinuities, reflecting changes in subglacial conditions arising from phases of more rapid margin retreat, separated by stillstands. Indeed, quantitative investigations of drumlin fields have often reported a transverse banding in their morphometry (e.g. Hill, 1973; Patterson and Hooke, 1995) which we take as a key indicator of a time-transgressively produced flow-set. Figure 3 illustrates these differences in morphometry and spatial pattern.

Landform associations can also be used as a guide. If a flow-set is accompanied by a series of marginally produced retreat moraines that are orthogonal to the lineation orientation, then it is safe to presume the whole land-system assemblage was laid down time-transgressively. A similar argument has been made for eskers that are found to lie in an approximately parallel arrangement with lineations (Kleman, 1990). Although there is still some debate (cf. Menzies and Shilts, 1996), sub- or englacial conduits and their sedimentary product, eskers, are usually regarded to be time-transgressive features, with formation occurring close to the ice margin as it steadily retreats (Hebrand and Årmark, 1989; Kleman and Borgström, 1996; Menzies and Shilts, 1996). If this interpretation is true for all eskers, then, when they are found in subparallel arrangement with lineations, they must record time-transgressive retreat patterns. This association of eskers and lineations is an extremely common occurrence for the Laurentide and Fennoscandian ice sheets, and is usefully described as a "wet-bed deglaciation fan" by Kleman and Borgström (1996).

The means of distinguishing between time-transgressive and isochronous lineament generation is thus by careful observation of flow topology, cross-cutting, the degree of parallel conformity and the nature of the spatial variation in morphometry. If a whole lineation field was generated in a single phase, we would expect the pattern to be well-organized, coherent and with no obvious discontinuities. But for formation arising from time-transgressive retreat, the pattern should be more variable with lineations displaying less-parallel conformity, and with cross-cutting patterns and abrupt changes in morphometry. Additionally, landform association with retreat moraines and eskers helps to confirm a timetransgressive mode of formation.

\section{BEDFORM PRESERVATION}

The preservation of land surfaces beneath ice sheets is an important issue in palaeoglaciology, as it is critical for determining ice-sheet extent (e.g. Sugden and Watts, 1977), for apportioning subglacial land-systems to specific glacials and times within them (e.g. Kleman and others, 1994; Boulton and Clark, 1990a, b) and for determining the thermal evolution of ice sheets (e.g. Sollid and Sørbel, 1994; Kleman and others, 1997).

Preservation of old landforms, surfaces and deposits beneath ice cover has long been reported (e.g. Ives, 1966; Sugden, 1968; Rose and Letzer, 1977; Sugden and Watts, 1977). More recently, it has been shown that preservation can easily occur and is, in fact, quite widespread (e.g. Kleman, 1994). There are numerous examples of surfaces, deposits and landforms that lie out of accord with known deglacial patterns 
a

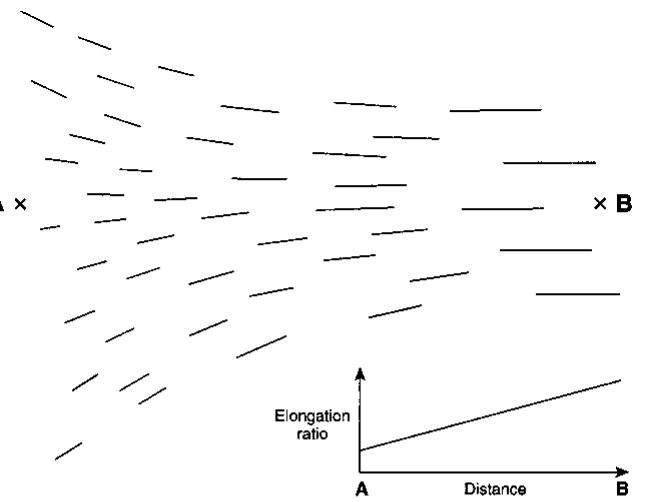

b

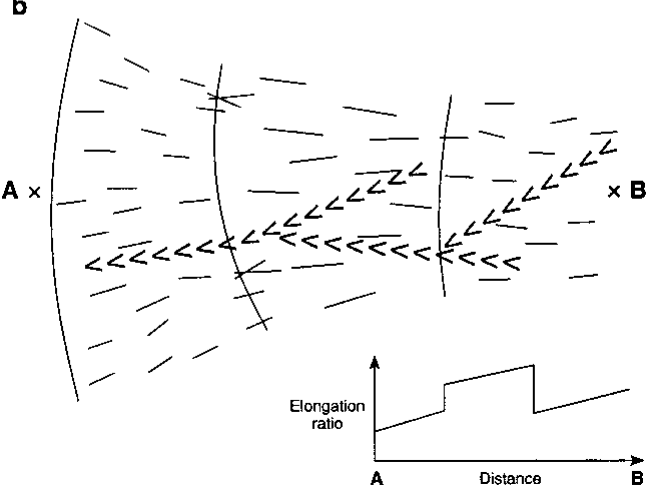

Fig. 3. Predicted characteristics of lineation pattern arising from isochronous (a) and time-transgressive (b) generation. An isochronously produced flow-set should contain lineations of high parallel conformity, no cross-cuts and with gradual variations in morphometry ( see inset graph of $A-B$ ). Conversely, for the time-transgressive case, we expect low parallel conformity, possible occurrence of cross-cuts and abrupt discontinuities in morphometry (transverse banding of inset graph). Associated and appropriately aligned eskers and end moraines provide further evidence.

and are therefore inferred to be preserved remnants from earlier in the glacial cycle or from previous glacials.

It is important at this stage to be clear as to what we mean by the term preservation. The purist form of preservation is where the actual land-surface is left virtually unmodified, which we can call surface preservation (Fig. 4a). Subglacial survival of periglacially produced stone circles is an example of this type (e.g. Goldthwait, 1960). Deposit preservation is a situation whereby older deposits have survived erasure but the current surface is in fact an erosional unconformity, such that we do not know how much of the original deposit is missing (Fig. 4b). A similar situation may also arise concerning the shape that defines a landform. A large drumlin, for example, may suffer considerable erosion by over-riding ice and, yet, the subdued form may still retain the characteristic shape of a drumlin leading us to identify it as such. This can be termed landform preservation (Fig. 4c). Larger landforms, such as mega-scale lineations, will have a stronger potential for preservation than smaller forms such as flutes. It is important not to confuse these different degrees of preservation, as we have a range of modification from none to perhaps up to tens of metres of erosion or modification. Unless the original land surface can be identified, deposit- and landform-preservation cannot be taken to indicate a complete lack of modification by subsequent ice flow. The impli-
Surface-preservation

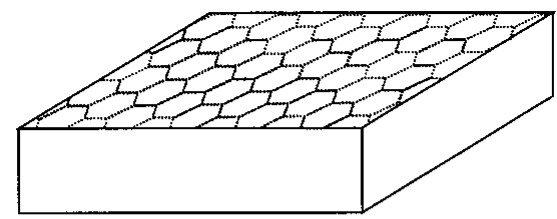

b. Deposit-preservation
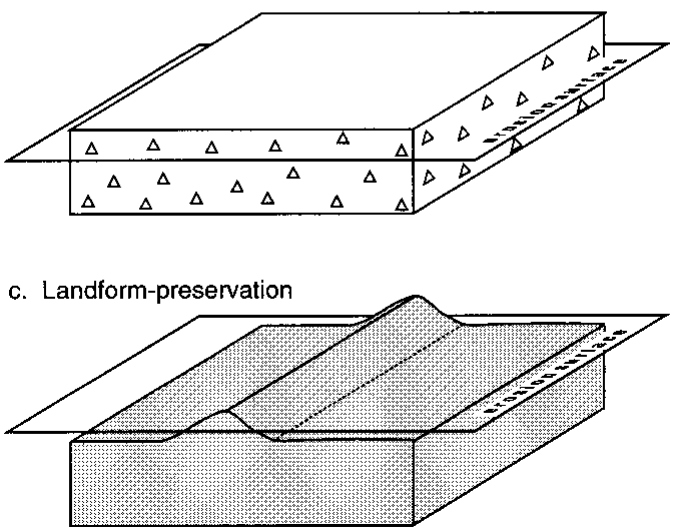

Fig. 4. Preservation beneath ice sheets can be split into three categories, depending upon the degree and depth of modification. Surface preservation requires no modification, whereby delicate features such as periglacial stone circles are protected. Yet for deposit and landform preservation, many metres of erosion/ modification may have taken place without this being apparent.

cation of the different degrees of preservation is that it should not be universally treated as a binary switch, which is either on or off. For the deposit- and landform-types of preservation, where modification is gradually occurring, the duration of flow will clearly be important.

A plausible and logically complete ice-sheet reconstruction requires a mechanism or explanation that accounts for the preservation of landscape patches. Simply put, we get preservation when basal shear-stress is lower than bed strength. Three possible explanations for subglacial preservation are explored below.

\section{Cold-based ice}

Ice below the pressure-melting point is likely to be frozen to its bed, thereby inhibiting any ice flow which shields the surface from modification and preserves existing landforms (Sugden and John, 1976; Sugden, 1978). This association between cold-based ice and landscape preservation has been widely applied in palaeoglaciology. The main weakness of application of the cold-based preservation mechanism to ice-sheet reconstructions, is our lack of understanding about the spatial distribution of thermal regime within an ice sheet and how it evolves through time. Modelled descriptions of the spatial distribution of thermal regime of steady-state ice sheets in equilibrium are available (e.g. Sugden, 1977) and yet we know that changes in ice-surface elevation, air temperatures, advection of cold ice and the positive feedback between flow velocity and strain heating make the problem much more complex (Hindmarsh and others, 1989; Hindmarsh, 1990, 1993). These complexities radically alter our ideas of the spatial distribution of thermal regime, so much so that we have moved from a general simplified model of warm-centred (Sugden, 1977) to cold-centred ice sheets (Hindmarsh and others, 1989; Huybrechts and T'siobbel, 
1995; Heine and McTigue, 1996), but whilst realizing that the actual evolution through the life of the ice sheet is likely to be still more complicated. Uncertainties in the physical modelling and parameterization of thermal evolution means that glacial geomorphologists simply do not have enough basic knowledge about thermal regime to use it as a guide for interpreting subglacial landscapes. By using the causal link between preserved landscapes and cold-based ice, glacial geomorphologists are now doing the reverse, that is using geomorphology to infer and map the thermal regime of former ice sheets (Dyke, 1993; Sollid and Sørbel, 1994; Kleman and others, 1994; Hättestrand, 1997; Clark and others, submitted). It remains to be seen if these reconstructions of the evolution of thermal regime are glaciologically plausible and herein lies a major challenge.

\section{Protection arising from low-velocity basal sliding}

Given that it was earlier argued that high ice velocities are required for the generation of subglacial lineations, the converse is likely to apply; that low velocities are not conducive for bedform generation and may leave subglacial geomorphology intact. Minor excavation and entrainment of sediments may be expected, which may leave all but the most delicate of features preserved. As ice divides have extremely low basal velocities, these are the most-favoured position for protection (Boulton and Clark, 1990b; Boulton, 1996). Alternatively, we can envisage a much larger zone of protection to include most of the ice sheet except for beneath ice streams, surges and the submarginal fast-flow zones. If this is the case, then deposit- and landform-preservation is the norm, but with specific zones of fast-flow causing erasure.

\section{Preservation by shallowing of deformation layer or basal uncoupling} The response of a bed of soft sediment to the normal and shear stresses applied by over-riding ice flow is highly dependent on meltwater production and drainage. This is because high pore-water pressures reduce bed strength which encourages deformation and hence modification of the geology and landforms of the bed. Figure 5 illustrates four possible hydrologically controlled states which a softsediment bed may experience. Different pore-water pressures exert a control on the strengths of the sediment and ice-bed interface. For very low water pressures, a stable rigid bed should exist, but with the surface experiencing some sliding, ploughing and limited brittle shear (Fig. 5c; Benn and Evans, 1998). Higher pore-water pressures will lower the sediment strength and promote ductile deformation which may be shallow (b) or deep (a) corresponding to a low or higher ice flux (Boulton, 1996). Very high pressures of pore water may weaken the ice-bed interface more than the sediment body and thus promote basal sliding ((d); Iverson and others, 1995; Piotroski and Kraus, 1997). To understand the potential for preservation, we must consider which states do not lead to actual surface lowering (i.e. erosion sensu stricto) or modification (reorganization of material). Deep deformation (a) is clearly going to reorganize the bed, and according to the deforming-bed model (Boulton, 1987; Hart, 1995), may actually generate new lineations. If we move from this state, arising from decreased ice flux or lower pwp, we have a shallower (b) or no deforming layer (c). Whilst both of these conditions are likely to modify the surface, preservation of large landforms and deposits should occur. Alternatively, a rise in pwp may lead to uncoupling of ice from the bed and basal sliding. This will also serve to preserve or, at least, minimally erode the underlying surface.

If all the preservation mechanisms discussed above were operable, then we must be cautious of simply ascribing occurrences of preservation to just one mechanism. It is tempting, for example, to ascribe all cases of preservation to coldbased ice as this is easiest to conceptualize in a reconstruction, whereas preservation that relies on low rates of modification requires extra considerations of the length of time for which it operates. In order to better reconstruct ice sheets, it would be ideal if we could distinguish between the types of preservation. This, however, is likely to be hard. A further complication is that the mechanisms may be inextricably linked. If we consider a situation of decreasing ice flux, the ice-bed interface will experience progressively less shear stress which will promote preservation, but there may also be a reduction in strain heating which may be enough to change the thermal regime from warm to cold-based.

\section{BEDFORM GENERATION AND PRESERVATION UNDER THE LABRADOR SEGTOR OF THE LAUR- ENTIDE IGE SHEET}

The Quebec-Labrador sector of the Laurentide ice sheet, Canada, is used to demonstrate how the preceding arguments can be used to help decipher glacial history from the bedform record. This sector formed one of three major components of the ice sheet during the Wisconsinan glaciation, covering an area $>3000000 \mathrm{~km}^{2}$ and probably reaching the order of $2 \mathrm{~km}$ in thickness. The bedform record was originally mapped from aerial photographs to produce the Glacial Map of Canada (Prest and others, 1968) and has been more recently mapped from satellite images (Boulton and Clark, 1990a, b; Clark and others, submitted). Using a variety of assumptions about the glaciodynamic contexts of lineation generation, there have been a number of radically different interpretations: that all bedforms were sheet-flow submarginally restricted, producing a deglacial reconstruction (Bryson and others, 1969; Boulton and others, 1985); sheet-flow pervasive, producing a maximal configuration (Shilts, 1980; Prest, 1984); or sheet-flow patch, recording a migrating ice divide (Boulton and Clark, 1990a, b). Whilst the former two models do not incorporate preservation of land systems in a significant way, Boulton and Clark (1990a, b) invoke protection beneath ice divides to explain aspects of their bedform record, which Kleman (1994) reinterprets using the distribution and character of meltwater channels to indicate cold-based ice as the preserving mechanism.

New mapping, along with the considerations of glaciodynamic context discussed in this paper, have permitted Clark and others (submitted) to produce a revized model of glacial history for the region. Lineations were grouped into flow-sets (Fig. 6a) and judged to be isochronously or time-transgressively produced according to the rules outlined earlier. In conjunction with associations with esker and moraine patterns, this allowed the glaciodynamic context of each flow-set to be ascertained, or assumed (Fig. 6b). When viewing the lineation characteristics, there is a striking contrast between those that comprise flow-set (a) which fulfil the time-transgressive criteria and have associated moraines and a dense and parallel network of eskers, and those that drain northwards (b) and $(\mathrm{d})-(\mathrm{g})$, which display the criteria of isochronous formation. 


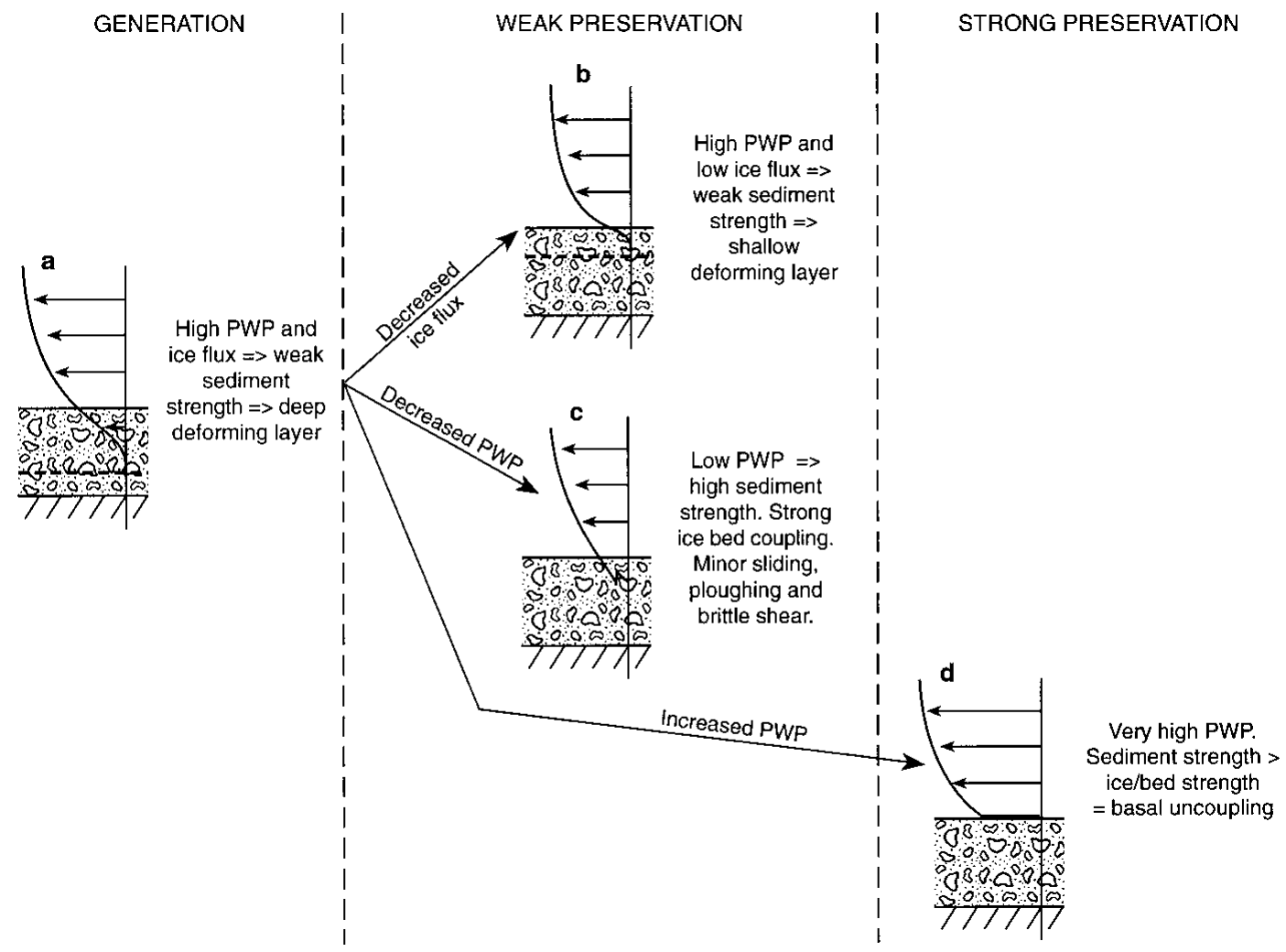

Fig. 5. Four hydrologically controlled states experienced by a soft-sediment bed, split into relative categories concerning their potential for generation and preservation. Deep deformation (a) will reorganize the bed and may generate new lineations. Moving from this state, arising from decreased ice flux or lower pwo, we have a shallower (b) or no deforming layer (c), both of which are likely to modify the surface, but may preserve deposits or large landforms. A rise in pwop (d) may lead to uncoupling of ice from the bed and basal sliding, minimally eroding the underlying surface.

To make sense of the overlapping flow-sets of Figure 6 requires a reconstruction with changing flow geometry and zones of lineation generation-preservation through time. Figure 7 illustrates a schematic version of part of the reconstructed flow history, which attempts to explain the context of lineation generation and preservation as the ice sheet retreated. Focusing on the main lineation sets, this reconstruction manages to explain why most of the lineations of flowsets (a) and (b) are extremely clear and well-formed, whilst those in the overlap region of (a)-on-(b) (see point Z, Fig. 6) are subtle and subdued. This is because they narrowly escaped erasure due to the brief period of lineament generation during deglaciation that overprinted flow-set (a). North of this area the lineations of flow-set (b) appear well-defined and fresh due to cold-based preservation.

\section{SUMMARY AND CONCLUSIONS}

Subglacially produced drift lineations have long been used to build or bolster ice-sheet reconstructions, even though we are unsure of their genesis and glaciodynamic context. Reconstructions of glacial history are highly sensitive to key assumptions we make, like when during the glacial cycle and where within the ice sheet they were generated. A hypothetical range of glaciodynamic contexts for lineament generation has been explored which include: sheet-flow submarginally restricted; sheet-flow pervasive; sheet-flow patch; ice stream; and surge or re-advance. Examples of each are provided. Sheet-flow pervasive is no longer regarded as a valid context for interpreting the lineament record. It is argued that the crux of deciphering the appropriate context is whether lineations within a group, or flow- set, were laid down time-transgressively or isochronously. The following characteristics are proposed for distinguishing between these styles of generation:

(1) predominantly splayed vs parallel-flow topologies;

(2) presence of within-flow-set cross-cutting of lineations;

(3) degree of parallel conformity;

(4) spatial variation in morphometry, as gradual or with abrupt discontinuities; and

(5) land-system associations with eskers or end moraines.

Application of these criteria to lineation patterns should help resolve uncertainty in interpreting the bedform record for palaeoglaciological reconstruction.

Increased discovery of complex bedform patterns, along with relict surfaces, landforms and deposits, has led us to realize that the erasure capability of ice sheets is much less than previously presumed. It is argued that preservation can be idealized as comprising three types: surface, deposit and landform preservation. Each requires a different degree of preservation, from high whereby delicate surfaces are protected, to low whereby an original landform can still be recognized in spite of metres of surface lowering or modification. The implication of this is that deposit- and landformtypes of preservation should not be treated as a binary switch which is either on or off, as modification is gradually occurring as a function of ice velocity and time (Fig. 8).

Possible explanations to account for the preservation of land-system patches are explored: cold-based ice; lowvelocity basal sliding under warm-based ice; shallowing of deformation layer; or basal uncoupling.

It is concluded that preservation by cold-based ice is un- 

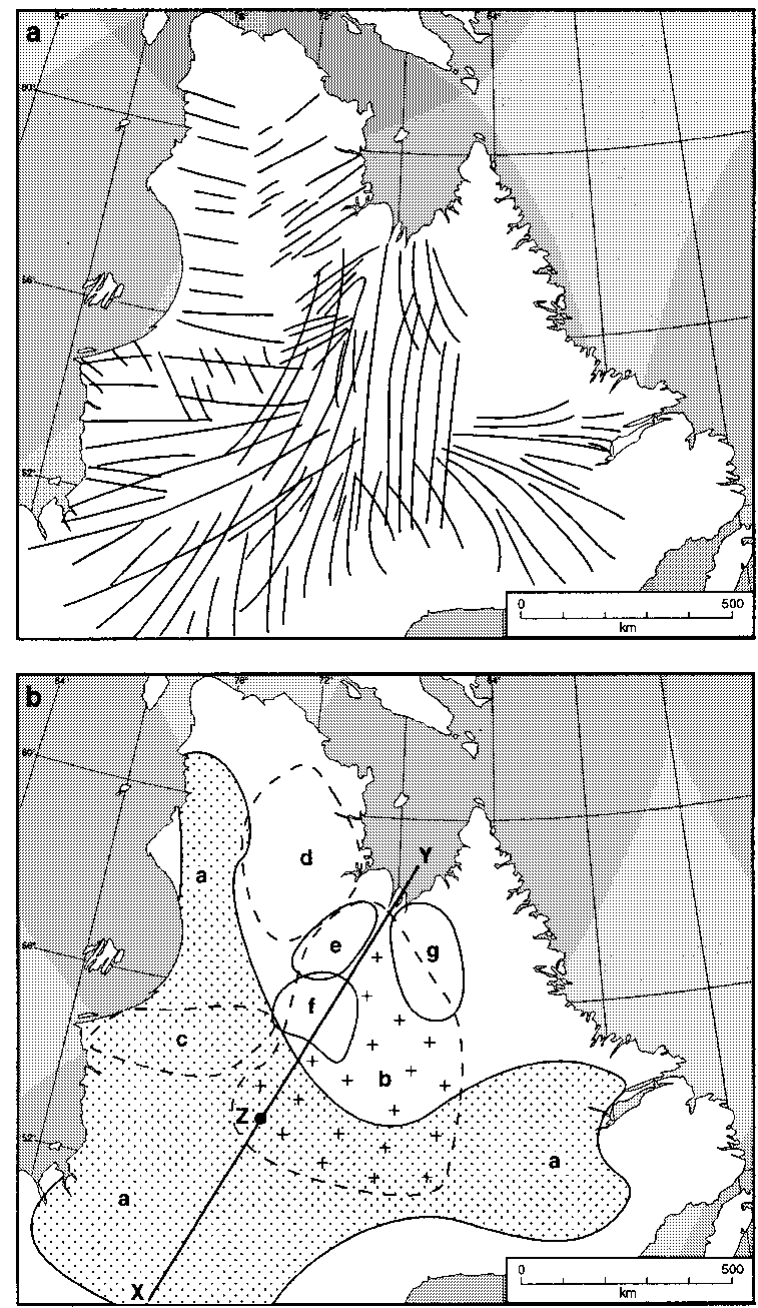

Fig. 6. (a) Subglacial drift lineations of Quebec-Labrador, summarized into flow-sets (after Clark and others, submitted). (b) Flow-sets arbitrarily referenced from (a) to ( $g$ ). Using the criteria described in this paper, flow-set (a) was produced time-transgressively and the rest generated isochronously. The inferred glaciodynamic contexts of flow-sets are as follows: (c) and (d) as sheet-flow patch; (b) as sheet-flow patch or surge; $(e),(f)$ and $(g)$ as ice streams; and the large set $(a)$ as sheet-flow submarginally restricted. Transect marked $X-1$ forms the basis of Figure 7 .

likely to account for the full range of relict land-system patches that are found, as protection is also likely to occur under warm-based ice. In these latter cases, ice velocity and hydrologic-control on sediment strength control the rate of modification, and the time elapsed determines the final amount of modification/preservation (Fig. 8).

The application of aspects of the ideas reported in this paper is made by reference to the bedform record of the Quebec-Labrador sector of the Laurentide ice sheet. A complex pattern of overlapping flow-sets can be interpreted in terms of generation and subsequent preservation by considering the thermal and basal shear-stress history of the ice sheet.

In conclusion, it is emphasized that patterns of subglacial drift lineations have a great deal of glacial history encoded in them, but we must be careful about making specific glaciodynamic assumptions as it greatly influences the nature of our final ice-sheet reconstruction. At the very least, the range of diversity of glaciodynamic contexts of generation and preservation should be considered, and

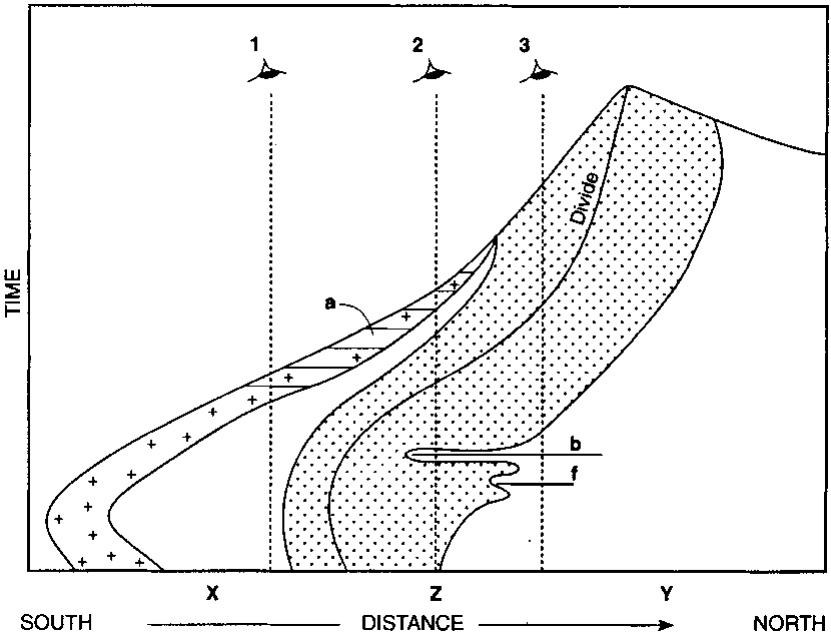

Fig. 7. Time-distance plot of a schematic reconstruction of icesheet history along transect $X-Y$ ( see Fig. 6) from glacial maximum until disappearance. This illustrates the context of lineament generation and preservation beneath an evolving ice sheet. The southern margin and ice divide retreated northwards, along with zones of cold-based ice (stippled), low velocity promoting preservation (blank), and lineation generation (crosses). Horizontal lines schematically illustrate the inferred glaciodynamic contexts of flow-sets, $(a),(b)$ and $(f)$. "Viewing" the glacial history along time-line 1 for a fixed point on the transect, we can see that at the glacial maximum the area experienced low velocity promoting preservation of possibly earlier-produced bedforms, but which were completely erased during passage of the lineation-generation zone producing flow-set ( a). The northsouth extent of (a) was built up time-transgressively behind the retreating margin. Time-line 2 illustrates the presumed warm-based surge event that isochronously produced flow-set (b). These landforms were preserved under cold-based ice and then, for a brief period during deglaciation, they experienced a new phase of lineament generation, subduing their form and overprinting a new pattern. This contrasts with time-line 3, where an ice stream $(f)$ and surge $(b)$ event produced bedforms that have been perfectly preserved beneath the retreating coldbase ice sheet. Note this is a theoretical reconstruction, as flowset activity, margin and divide migration etc. are not dated.

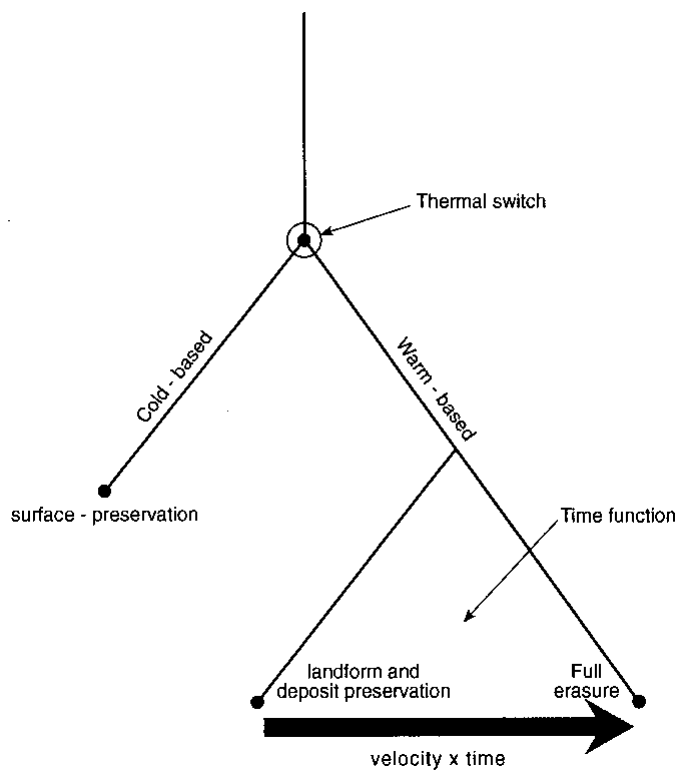

Fig. 8. Degrees of preservation idealized as being controlled by a thermal switch and a time function. 
where possible spatial analysis of lineation patterns should be made to narrow the uncertainties.

\section{ACKNOWLEDGEMENTS}

J. Kleman and P. Jansson are thanked for their helpful comments on an earlier version of this paper

\section{REFERENGES}

Benn, D. I. and D. J. A. Evans. 1998. Glaciers and glaciation. London, Arnold.

Bouchard, M. A. 1989. Subglacial landforms and deposits in central and northern Quebec, Canada, with emphasis on rogen moraines. Sediment. Geol., 62(3-4), 293-308.

Boulton, G. S. 1987. A theory of drumlin formation by subglacial sediment deformation. In Menzies, J. and J. Rose, eds. Drumlin Symposium. Rotterdam, A. A. Balkema, 25-80.

Boulton, G. S. 1996. Theory of glacial erosion, transport and deposition as a consequence of subglacial sediment deformation. f. Glaciol., 42(140), 43-62.

Boulton, G. S. and C. D. Clark. 1990a. A highly mobile Laurentide ice sheet revealed by satellite images of glacial lineations. Nature, 346(6287), 813-817.

Boulton, G. S. and C. D. Clark. 1990b. The Laurentide ice sheet through the last glacial cycle: the topology of drift lineations as a key to the dynamic behaviour of former ice sheets. Trans. R. Soc. Edinburgh, Ser. Earth Sci., 81 (4), 327-347.

Boulton, G. S., G. D. Smith, A. S. Jones and J. Newsome. 1985. Glacial geology and glaciology of the last mid-latitude ice sheets. 7. Geol. Soc., London, $142(3), 447-474$.

Bryson, R. A., W. M. Wendland, J. D. Ives and J.T. Andrews. 1969. Radiocarbon isochrones and the disintegration of the Laurentide ice sheet. Arct. Alp. Res., 1(1), 1-14.

Clark, C. D. 1993. Mega-scale glacial lineations and cross-cutting ice-flow landforms. Earth Surf. Processes Landforms, 18(1), 1-29.

Clark, C. D. 1994. Large-scale ice moulding: a discussion of genesis and glaciological significance. Sediment. Geol., 91 (1-4), 253-268.

Clark, C. D. 1997. Reconstructing the evolutionary dynamics of former ice sheets using multi-temporal evidence, remote sensing and GIS. Quat. Sci. Rev., 16(9), 1067-1092.

Dongelmans, P.W. 1995. Glacial dynamics of the Fennoscandinavian ice sheet: a remote sensing study. (Ph.D. thesis, University of Edinburgh.)

Dredge, L. A. and W. R. Cowan. 1989. Quaternary geology of the southwestern Canadian Shield. In Fulton, R. J., ed. Quaternary geology of Canada and Greenland. Geology of Canada 1. Ottawa, Ont., Geological Survey of Canada; Boulder, CO, Geological Society of America, 214-249. (The Geology of North America K-1.

Dyke, A. S. 1993. Landscapes of cold-centred Late Wisconsinan ice caps, Arctic Canada. Prog. Phys. Geogr., 17 (2), 223-247.

Dyke, A. S. and T. F. Morris. 1988. Drumlin fields, dispersal trains, and ice streams in Arctic Canada. Can. Geogr., 32(1), 86-90.

Dyke, A. S. and V. K. Prest. 1987. Late Wisconsinan and Holocene history of the Laurentide ice sheet. Géogr. Phys. Quat., 41 (2), 237-263.

Goldthwait, R. P. 1960. Study of ice cliff in Nunatarssuaq, Greenland. SIPRE Tech. Rep. 39.

Hättestrand, C. 1997. Ribbed moraines in Sweden - distribution pattern and paleoglaciological implications. Sediment. Geol., 111(1-4), 41-56.

Hart, J. K. 1995. Subglacial erosion, deposition and deformation associated with deformable beds. Prog. Phys. Geogr., 19(2), 173-191.

Hebrand, M. and M. Åmark. 1989. Esker formation and glacier dynamics in eastern Skåne and adjacent areas, southern Sweden. Boreas, 18(1), 67-81.

Heine, J. T. and D. F. McTigue. 1996. A case for cold-based continental ice sheets - a transient thermal model. F. Glaciol., 42(140), 37-42.

Hill, A. R. 1973. The distribution of drumlins in County Down, Ireland. Ann. Assoc. Am. Geogr., 63(2), 226-240.

Hindmarsh, R. C. A. 1990. Time-scales and degrees of freedom operating in the evolution of continental ice-sheets. Trans. R. Soc. Edinburgh, Ser. Earth Sci., 81(4), 371-384.

Hindmarsh, R. C. A. 1993. Modelling the dynamics of ice sheets. Prog. Phys. Geogr., 17 (4), 391-412.

Hindmarsh, R. C. A., G. S. Boulton and K. Hutter. 1989. Modes of operation of thermo-mechanically coupled ice sheets. Ann. Glaciol., 12, 57-69.

Hodgson, D. A. 1994. Episodic ice streams and ice shelves during retreat of the northwesternmost sector of the Late Wisconsinan Laurentide ice sheet over the central Canadian Arctic Archipelago. Boreas, 23(1), 14-28.

Hollingworth, S. E. 1931. Glaciation of western Edenside and adjoining areas and drumlins of the Edenside and Solway basin. Q. .7. Geol. Soc. London, 87(3), 281-359.

Huybrechts, P. and S. T'siobbel. 1995. Thermomechanical modelling of
Northern Hemisphere ice sheets with a two-level mass-balance parameterization. Ann. Glaciol., 21, 111-116.

Iverson, N. R., B. Hanson, R. LeB. Hooke and P. Jansson. 1995. Flow mechanism of glaciers on soft beds. Science, 267(5194), 80-81.

Ives, J. D. 1966. Block fields, associated weathering forms on mountain tops and the nunatak hypothesis. Geogr. Ann., 48A(4), 220-223.

Jansson, K. N. andJ. Kleman. 1999. The horned crag-and-tails of the Ungava Bay landform swarm, Quebec-Labrador, Canada. Ann. Glaciol., 28 (see paper in this volume).

Kleman, J. 1990. On the use of glacial striae for reconstruction of paleo-ice sheet flow patterns: with application to the Scandinavian ice sheet. Geogr. Ann., 72A(3-4), 217-236.

Kleman, J. 1994. Preservation of landforms under ice sheets and ice caps. Geomorphology, 9(1), 19-32.

Kleman, J. and I. Borgström. 1996. Reconstruction of palaeo-ice sheets: the use of geomorphological data. Earth Surf. Processes Landforms, 21 (10), 893-909.

Kleman, J., I. Borgström and C. Hättestrand. 1994. Evidence for a relict glacial landscape in Quebec-Labrador. Palaeogeogr., Palaeoclimatol., Palaeoecol., 111 (3-4), 217-228.

Kleman, J., C. Hättestrand, I. Borgström and A. Stroeven. 1997. Fennoscandian palaeoglaciology reconstructed using a glacial geological inversion model. f. Glaciol., 43(144), 283-299.

Lundqvist, J. 1986. Late Weichselian glaciation and deglaciation in Scandinavia. Quat. Sci. Rev., 5(1-4), 269-292.

MacAyeal, D. R. 1993. Binge/purge oscillations of the Laurentide ice sheet as a cause of the North Atlantic's Heinrich events. Paleoceanography, 8(6), 775-784.

Menzies, J. and W.W. Shilts. 1996. Subglacial environments. In Menzies, J., ed. Past glacial environments, sediments, forms and techniques. Vol. 2. Glacial environments. Oxford, etc., Butterworth-Heinemann, 15-136.

Mooers, H. D. 1989. Drumlin formation: a time transgressive model. Boreas, 18(2), 99-107.

Patterson, C. J. 1998. Laurentide glacial landscapes: the role of ice streams. Geology, 26(7), 643-646.

Patterson, C. J. and R. LeB. Hooke. 1995. Physical environment of drumlin formation. F. Glaciol., 41 (137), 30-38.

Piotrowski, J. A. and A. M. Kraus. 1997. Response of sediment to ice-sheet loading in northwestern Germany: effective stresses and glacier-bed stability. 7. Glaciol., 43(145), 495-502.

Prest, V. K. 1984. The Late Wisconsinan glacier complex. Geol. Surv. Can. Pap. 84-10, 22-36.

Prest, V. K. 1990. Laurentide ice-flow patterns: a historical review, and implications of the dispersal of Belcher Islands erratics. Géogr. Phys. Quat., 44(2), 113-136.

Prest, V. K., D. R. Grant and V. N. Rampton. 1968. Glacial map of Canada. Scale 1:5,000,000. Ottawa, Ont., Geological Survey of Canada. (GSC Map 1253A.)

Punkari, M. 1995. Functions of the ice streams in the Scandinavian ice sheet: analyses of glacial geological data from southwestern Finland. Trans. R. Soc. Edinburgh, Ser. Earth Sci., 85, 283-302.

Rose, J. and J. M. Letzer. 1977. Superimposed drumlins. F. Glaciol., 18(80), $471-480$.

Shaw, J. 1994. A qualitative view of sub-ice-sheet landscape evolution. Prog. Phys. Geogr., 18(2), 159-184.

Shilts, W.W. 1980. Flow patterns in the central North American ice sheet. Nature, 286(5770), 213-218.

Smalley, I. J. and D. J. Unwin. 1968. The formation and shape of drumlins and their distribution and orientation in drumlin fields. F. Glaciol., 7(51), 377-390.

Sollid, J. L. and L. Sørbel. 1994. Distribution of glacial landforms in southern Norway in relation to the thermal regime of the last continental ice sheet. Geogr. Ann., 76A(1-2), 25-35.

Stokes, C. R. and Clark, C. D. 1999. Geomorphological criteria for identifying Pleistocene ice streams. Ann. Glaciol., 28 (see paper in this volume).

Sugden, D. E. 1968. The selectivity of glacial erosion in the Cairngorm Mountains, Scotland. Inst. Br. Geogr. Trans., 45, 79-92.

Sugden, D. E. 1977. Reconstruction of the morphology, dynamics and thermal characteristics of the Laurentide ice sheet at its maximum. Arct. Alp. Res., 9(1), 21-47.

Sugden, D. E. 1978. Glacial erosion by the Laurentide ice sheet. F. Glaciol., 20 (83), 367-391.

Sugden, D. E. and B. S. John. 1976. Glaciers and landscape; a geomorphological approach. London, Edward Arnold.

Sugden, D. E. and S. H. Watts. 1977. Tors, felsenmeer, and glaciation in northern Cumberland Peninsula, Baffin Island. Can. 7. Earth Sci., 14(12), 2817-2823.

Synge, F. M. 1970. The Irish Quaternary: current views 1969. In Stephens, N. and R. E. Glasscock, eds. Irish geographical studies. Belfast, The Queens University, 34-48. 